\title{
Visitors' Attachment to Historic Tourism Places in Kuala Lumpur City Centre towards Sustainable Urban Regeneration
}

\author{
Norsidah Ujang, Amine Moulay, Juriah Zakaria \\ Department of Landscape Architecture , Faculty of Design and Architecture, \\ Universiti Putra Malaysia, 43400 Serdang, Selangor Malaysia \\ norsidah@upm.edu.my, archiamine@gmail.com, juriahza@gamil.com \\ $+60389464071$
}

\begin{abstract}
This paper discusses visitors' attachment to historic tourism places in the city of Kuala Lumpur in the context of urban regeneration. The study found that despite having a short duration of visits, the visitors' functional and emotional attachment to attractions was fairly strong. Future regeneration of the places has been linked to improvement of the physical setting and preservation of historic places. The visitors identified strongly with the cultural image and the need to experience the places with comfort. Sustainable urban regeneration within the tourism context demands a good understanding of place attachment reflected in the relationship between people and the destinations that go beyond the attractive image of tourism places.
\end{abstract}

Keywords: urban regeneration; urban tourism; place attachment

eISSN: 2398-4287 @ 2018. The Authors. Published for AMER ABRA cE-Bs by e-International Publishing House, Ltd., UK. This is an open access article under the CC BYNC-ND license (http://creativecommons.org/licenses/by-nc-nd/4.0/). Peer-review under responsibility of AMER (Association of Malaysian Environment-Behaviour Researchers), ABRA (Association of Behavioural Researchers on Asians) and cE-Bs (Centre for Environment-Behaviour Studies), Faculty of Architecture, Planning \& Surveying, Universiti Teknologi MARA, Malaysia.

https://doi.org/10.21834/e-bpj.v3i9.1521

\subsection{Introduction}

Regeneration of urban places is one of the key urban development agenda to promote urban tourism. Tourism has become one of the main activities in major cities of Malaysia. The agenda is supported by the Eleventh Malaysian Plan (2016-2020) to encourage the provision of conducive environment enabling the tourism sector to grow. In this regard, although the capital city of Malaysia, Kuala Lumpur plays a pivotal role in the development and growth of the national tourism industry (KLCH, 2015). However, due to isolated concerns and initiative, urban regeneration has not been structured to allow for a meaningful tourism experience while some of the potential attractions remain inaccessible and unknown to visitors. The tourists' relationship with destinations could be measured by place attachment. When people develop an attachment with places, it could potentially lead to satisfaction and return visitations (Ujang \& Shuhana, 2008). This paper explores place attachment as a socio-psychological component of a place that defines the relationship between people and places of attraction. It is discussed in relation to urban regeneration ideas and preference within historic places in the city of Kuala Lumpur. Urban regeneration relates to improvement and transformation for the benefit of social, economic and the environmental aspects of place. In the context of this study the scope is confined to the physical redevelopment or improvement of spaces and places and their physical imagery and character. These aspects influence the tourists' experience of the places of attraction.

\subsection{Literature Review}

eISSN: 2398-4287 @ 2018. The Authors. Published for AMER ABRA cE-Bs by e-International Publishing House, Ltd., UK. This is an open access article under the CC BYNC-ND license (http://creativecommons.org/licenses/by-nc-nd/4.0). Peer-review under responsibility of AMER (Association of Malaysian Environment-Behaviour Researchers), ABRA (Association of Behavioural Researchers on Asians) and CE-Bs (Centre for Environment-Behaviour Studies), Faculty of Architecture, Planning \& Surveying, Universiti Teknologi MARA, Malaysia. https://doi.org/10.21834/e-bpj.v3i9.1521 
Many developing countries recognise tourism as the engine of growth in their effort to economically develop their countries, where the case in Malaysia is of no exception, considering tourism sector as a real wealth generator (Awang \& Abd Aziz, 2011). While other forms of tourism have experienced spectacular growth in the ${ }^{`} 60 \mathrm{~s}-{ }^{`} 70 \mathrm{~s}$, during which tourism was associated with the movement of residents from urban areas into tourist resorts and to rural areas, urban tourism has enjoyed the specialists focus only since the 80 's, when it became clear that many cities have turned into major tourist destinations. Urban tourism is one of the most dynamic forms of tourism. It covers three elements, the tourist, the tourism industry and cities (Craggs \& Schofield, 2011). Also, it is made up of the primary elements such as visitor attractions with the ability to attract tourists, and secondary elements such as transportation used by tourists to travel to the destination or as services after arrival (Cave \&, 2012). Urban tourism refers to travels inside cities or areas with a high population density. It refers both to the movement of tourists in cities or urban agglomerations of at least 20,000 people outside their main residence, subject to remaining at least one night at the destination and the tourist movement to less than 24 hours in the urban area, provided that the travel distance to be at least $100 \mathrm{~km}$ (Morgan et al, 2004). Public space plays an important role in the development of city particularly in the aspects of improving tourism development and liveliness of the city (Ramlee et al., 2018). However, without a proper revitalization strategy to uphold place qualities (in this case heritage streets), the place will be deteriorated and lose its attraction (Samadi \& Mohd Yunus, 2018) The involvement of relevant stakeholders with decision making in the future of their cities is important, as the locals are the end-users of every regeneration scheme (Said, 2018).

\subsection{Place Attachment and tourism experience}

Place attachment is defined by "the development of affective bond or link between people or individuals and specific places" (Moore and Graefe, 1994). It is expressed through "interplay of affects and emotions, knowledge and beliefs, and behaviours and actions" (Altman \& Low, 1992). Place attachment is also reflected in the functional bonding between people and places described as place dependence). In this case, the achievement of highly valued goals will produce more positive feelings toward a place than will the attainment of minor goals. It is also related to the functional quality of the physical elements and activities that are distinct from other places, which is central to good urban design quality. Hidalgo and Hernandez (2001) relate place attachment to the desire to maintain closeness to the object of attachment which also describes the special feeling towards a particular place. In the context of the study, this can be associated with elements of attraction, the frequency of visits and the emotional reactions towards the place. Place dependence is associated with functional attachment reflects the importance of a place in providing features and conditions that support specific goals or desired activities (Stokols and Shumaker, 1981). In this case, the achievement of highly valued goals will produce more positive feelings toward a place than will the attainment of minor goals. Thus, the degree to which a person feels attached to, or dependent on, a place is a function of how well his or her needs, goals, or motivations are satisfied or how positive he or she perceives his or her experiences to be in that location.

Moore and Graefe (1994) associated place dependence with the perceived strength of association between a person and specific place - the degree to which occupants perceive themselves to be strongly associated with and dependent on a particular place. According to Smaldone (2005), place dependence comes from a person's consideration of two things : (a) the quality of the current place and (b) the quality of other substitute places that are comparable to the current place. It concerns the functional and utilitarian aspects of place attachment (Stokol and Shumaker, 1981). It can be related to the functional quality of the physical elements and activities that is distinct from other places, which is central to urban design quality and assessment of successful places including in particular tourism places.

Place attachment constructs have been discussed in the context of tourism places (Moore and Graefe, 1994) on attachment to recreational setting and the relationship between involvement and place attachment within a tourism context based on the measurement of place dependence and place identity and respondents' attitudes towards tourism experiences Gross et al. (2008). It can be measured regarding the relationship among tourists' involvement, place attachment and interpretation satisfaction Hwang, Lee \& Chen (2005). They sought to show the potential utility of place attachment using related constructs as a resource management tool in different types of recreational settings. The relevant question is how place attachment relates to future changes of historic places and the users' views on the future image of the places. This paper examines the place attachment dimensions in relation to the idea of regeneration of places in the city of Kuala Lumpur. This paper should provide a framework in the form of criteria and priorities to further the analysis. It is hopeful that in the final stage of the study and based on the preliminary findings, the researcher can identify if place attachment dimensions contribute to the tourists' preference for urban regeneration ideas.

\subsection{Methodology}

The paper is based on a pilot survey conducted with 50 visitors in tourist attraction areas in Kuala Lumpur city centre. The areas are Dataran Merdeka (Merdeka Square), Chinatown, Kampong Bharu, Jalan Masjid India (see Figure 1) and Brickfields (located just outside the centre of Kuala Lumpur) which are regarded as the cultural tourism places that sustain their image and identity in the midst of progress and development of the city. The inquiry consists of the respondents' profile, engagement pattern (frequency of visits, purpose of visit and place attraction), place attachment (functional attachment, emotional attachment, future engagement), elements of regeneration and future image of the places (business tourism, leisure and cultural tourism). The analysis will also include the first time visitors based on their perception and knowledge about the place, however this category of respondents will not be included in the final survey. The field observation using photo recording to examine the existing 
condition of the places in light of the regeneration ideas. The samples were randomly selected from the foreign and local visitors, who were in the sites/locations at the time of the survey and willing to participate. In the case where a constant flow of users at different intensity, the total number of population within the streets cannot be easily identified. Based on the principle that the size of the population sample from which the sample was drawn is irrelevant for the accuracy of the sample, the sample size drawn for this survey is generated based on the calculation using 5.5\% sampling error at 95\% confidence level (De Vaus, 1991). The size indicates that a total of 330 respondents should participate in the survey. For this paper, the pilot study results are presented from 50 samples and the observation data to be able to commence with the final survey. Descriptive analyses are used to provide a simple summary of the data as well as analysing the demographic profile using frequency and means. Data from direct observation is analysed based on photographic identification and analysis and description of key visual elements. Data from the open-ended questions will be presented based on the respondents' opinions on the types of development and what should be improved if the area were to be undergoing regeneration. Cronbach Alpha coefficient was used to measure the reliability of the instruments. In the current study, the variable that has Cronbach Alpha coefficient value equal or more than 0.7 was regarded as reliable instrument (Pallant, 2013). The results showed all the variables are reliable except leisure and culture. The items for Emotional attachment (Cronbach apha= 0.831) and Business tourism (Cronbach apha 0.802 ) have relatively high internal consistency.

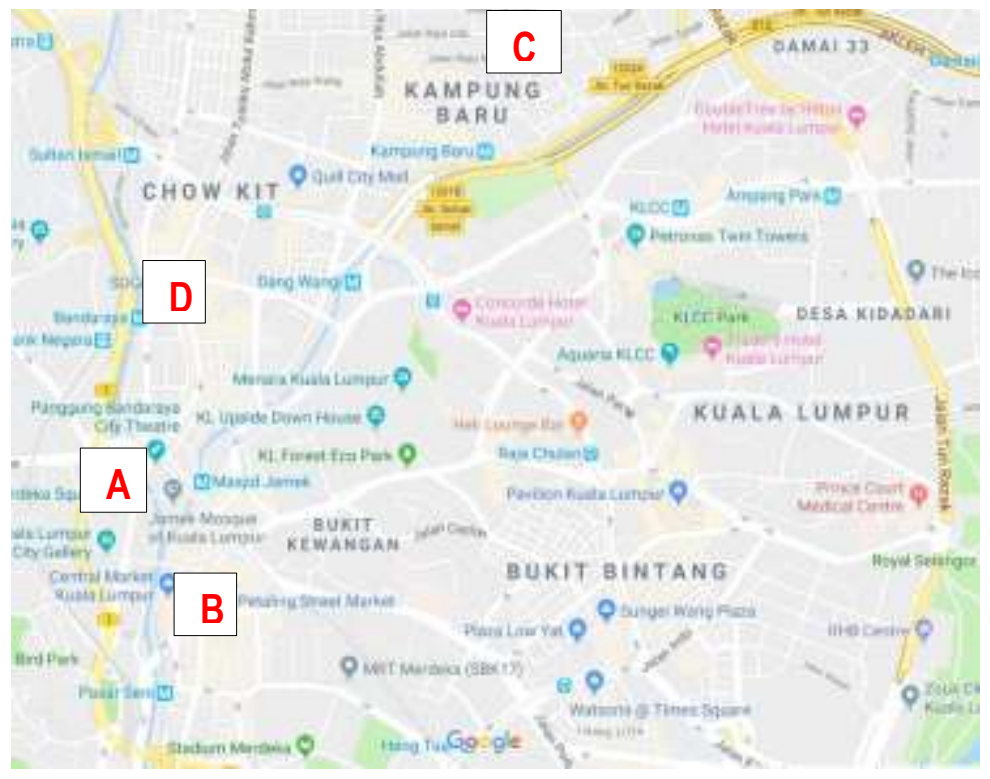

Fig. 1 Locations of Dataran Merdeka (Merdeka Square) (A), Chinatown (B), Kampong Bharu (C), Jalan Masjid India (D)

\subsection{Findings}

\subsection{Respondents' profiles}

The main subjects in the study are visitors, and the proportion of local and foreign visitor were 68.0 and 32.0 per cent, respectively. Almost half of them (44 per cent) aged between 26 to 35 years old, followed by 30.0 per cent were aged between 18 to 25 years old. The remaining respondents were aged between 36 to 45 years old ( 8.0 per cent), between 46 to 55 years old (10 per cent). Most of them are female (68 per cent), and 32 per cent were male. More than half ( 62.0 per cent) of the respondents were married, 36.0 per cent were single, and 2.0 per cent were others. 54.0 per cent of the respondents have income less than RM4, 000 and 46.0 per cent income between RM4, 000 to RM12, 000. Most of the respondents (64.0 per cent) have a bachelor degree, 16.0 per cent diploma, 16.0 master and above, and 4.0 per cent secondary school. Regarding residency, about 70 per cent of the respondents lived in Peninsular Malaysia, 26.0 per cent from overseas and 4.0 per cent lived in Kuala Lumpur.

\subsection{Pattern of engagement}

Almost half of the respondents (44.0 per cent) visited the place as the first timer while others visited the places several times (32.0 per cent). 12.0 percent of the respondents visit the place once a year, 8.0 per cent visit monthly and only 4.0 per cent of the respondents visited the place weekly. 38.0 per cent visited the place more than once, and 18.0 per cent of them visited the places frequently. Most of the respondents (78.0 per cent) found the places attractive for leisure activities. More than half (52.0 per cent) of the respondents stated that they would make sure that they visit all the attractions in the city during their stay in that place. 42.0 per cent of the respondents indicated that their main purpose to visit the place is for leisure activities while 42.0 per 
cent of them visit the place is for general sightseeing. The remaining of the respondents stated that they came to the place for business (8.0 per cent), shopping (6.0 per cent) and eating (2.0 per cent). More than half of the respondents (60.0 per cent) spend the short trip in Kuala Lumpur, 32.0 per cent of them for transit and only 8.0 per cent was for a long trip. Most of the respondent ( 80 per cent) travelled in a group of fewer than five persons, 12.0 per cent travel individually and the rest 8.0 per cent travelled in a group of more than five persons. They were visiting with friends, partners and families.

\subsection{Place attachment}

This survey uses 5 points Likert scale (strongly disagree to strongly agree). The results on place attachment are shown in Table 1. The mean score of the functional attachment was 3.40 which indicate the respondents have a fairly strong functional attachment to the places they visited. The respondents agree that walking around the place is the best thing to do $(\mathrm{m}=3.68)$ and the place provides them with what they want as a tourist $(m=3.62)$. The lowest mean score was 3.04 whereby the respondents slightly agree that the place offers good resting opportunities.

Regarding emotional attachment, the mean score was 3.47 which indicates a fairly strong emotional attachment to the places. The highest mean score was 3.76 indicating the respondents' agreement that the image of the place is memorable to them. The respondents also agreed that staying in that place makes them happy. The respondents slightly agree that the place is meaningful to them $(m=3.30)$. For the items to indicate future engagement of the places, this survey uses 5 points Likert scale (very unlikely to very likely). The mean score of the place attachment regarding use was 3.72. The results indicated the highest mean score was 3.94. The respondents were very likely to return to the place in the near future. The respondents also wished they can spend more time in that place $(m=3.32)$.

Table 1. Place Attachment

\begin{tabular}{|c|c|c|c|}
\hline Category & Items & Mean & $\begin{array}{l}\text { Std. } \\
\text { Deviation }\end{array}$ \\
\hline \multirow{5}{*}{$\begin{array}{l}\text { Functional Attachment } \\
\text { Mean }=3.40(S D=.523)\end{array}$} & Walking around this place is the best thing to do & 3.68 & .741 \\
\hline & This place provide me with what I want as a tourist & 3.62 & .697 \\
\hline & I feel the need to visit this place every time I come to the city & 3.38 & .780 \\
\hline & This place is very important for me to visit while in the city & 3.30 & .580 \\
\hline & This place offers good resting opportunities & 3.04 & .727 \\
\hline \multirow{6}{*}{$\begin{array}{l}\text { Emotional Attachment } \\
\text { Mean }=3.47(S D=.565)\end{array}$} & The image of this place is memorable to me & 3.76 & .687 \\
\hline & Staying in this place makes me happy & 3.60 & .670 \\
\hline & I appreciate the beauty of the landscape here & 3.58 & .906 \\
\hline & I enjoy being here more than any other place & 3.36 & .851 \\
\hline & This place is meaningful to me & 3.30 & .735 \\
\hline & I feel secure being in this place & 3.20 & .728 \\
\hline \multirow{4}{*}{$\begin{array}{l}\text { Place Attachment [Future } \\
\text { engagement] } \\
\text { Mean }=3.72(S D=.528)\end{array}$} & I will return to this place in the near future & 3.94 & .652 \\
\hline & I will recommend this place to others & 3.90 & .505 \\
\hline & I will explore this place further & 3.82 & .629 \\
\hline & I will spend more time in this place & 3.32 & .794 \\
\hline
\end{tabular}

(Source: the Author, 2018)

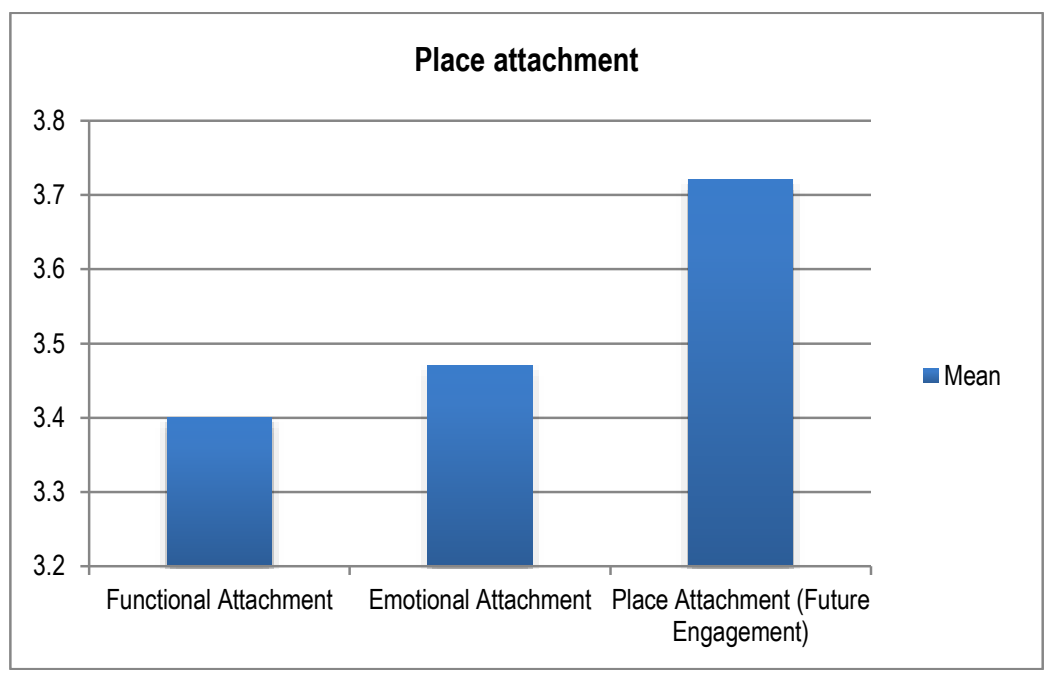

Fig. 2 Place attachment to tourism places

\subsection{Place regeneration}

The results on the type of development that the respondents preferred to have if the place were to change due to urban regeneration are presented in Table 2. This survey uses 5 points Likert scale (strongly disagree, disagree, neutral, agree and 
strongly agree). The types of regeneration ideas were categorised as business tourism, social events, historic attractions, retail activities and leisure and culture. The respondents strongly identified historic attractions $(m=3.79)$ and leisure and culture $(\mathrm{m}=3.77)$ as their preferred types of tourism development. The respondents were very much interested to see historic attraction and marketplaces in that place in the future. However, they were less interested in religious buildings. The respondents were very interested to see parks and open spaces develop in that place for staying and relaxing in the future. The respondents also would like to see traditional and cultural centres, but they were not very interested in music centres. The respondents did not feel that conference places should be part of the place. The respondents agreed that the cultural events are the events they would like to see in that place in the future. However, they did not prefer sporting events as part of the future elements in the city. The mean score of the retails activities was 3.61. The respondents strongly agreed that the place should have traditional markets and street vendors as the elements of attraction. In this regards, the respondents were less interested in sales promotions, megamalls and hypermarkets.

Table 2. Place Regeneration Preference

\begin{tabular}{llll}
\hline Category & Items & Mean & $\begin{array}{l}\text { Std. } \\
\text { Deviation }\end{array}$ \\
\hline Business tourism & Trade fairs & 3.50 & .814 \\
Mean =3.18 SD=.666 & Areas for exhibition halls & 3.22 & .815 \\
& Health and medical hub & 3.16 & .866 \\
& Educational hub & 3.12 & 1.100 \\
& Conferences places & 2.92 & .829 \\
\hline Social events & Cultural events & 3.92 & .752 \\
Mean $=3.59$ SD=.691 & Artistic events & 3.82 & .774 \\
& Sporting events & 3.04 & .968 \\
\hline Historic Attraction & Historic attraction & 3.96 & .903 \\
Mean =3.79 SD=.641 & Market places & 3.96 & .807 \\
& Museums and art galleries & 3.94 & .712 \\
& Religious buildings & 3.30 & 1.055 \\
\hline Retails activities & Traditional market & 3.80 & .969 \\
Mean $=3.61 \mathrm{SD}=.727$ & Street vendors & 3.80 & .904 \\
& Shopping stores & 3.64 & 1.025 \\
& Sales promotions & 3.42 & 1.090 \\
& Megamalls and Hypermarkets & 3.40 & .969 \\
\hline Leisure and culture & Parks and open spaces to stay and relax & 4.16 & .817 \\
Mean =3.77 SD=.566 & Traditional and cultural centres & 4.06 & .712 \\
& Food junctions & 3.84 & .766 \\
& Waterfront & 3.46 & .973 \\
& Music centre & 3.34 & .939 \\
\hline
\end{tabular}

(Source: the Author, 2018)

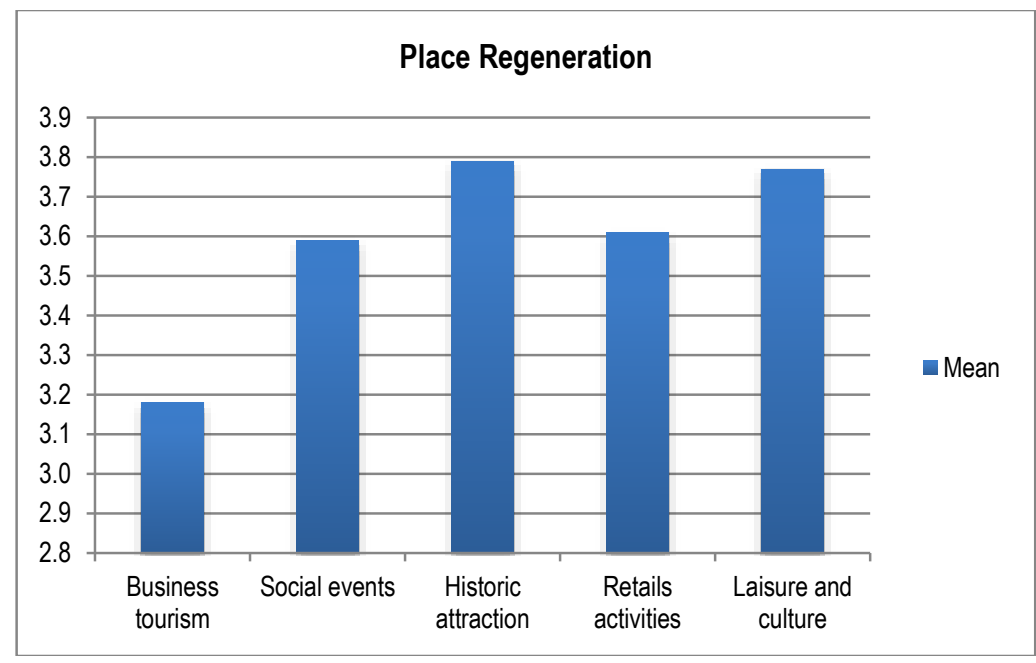

Fig. 3 Place regeneration preference

\subsection{Place improvement}

Results shown in Table 3 indicate the respondents' feedback on place improvement. About 28.6 per cent suggested that there should be more greenery and parks. Others mentioned the need to increase parking spaces and pedestrian facilities. About 10.7 per cent stated that the place is good enough and does not require changes. The respondents also suggested that the walkways, security, sales, halal food, tourist attractions spots should be increased. 
Table 3. Place Improvement

\begin{tabular}{lll}
\hline Themes & Frequency & Percentage \\
\hline Greenery and parks & 8 & 28.6 \\
Parking spaces & 5 & 17.9 \\
Pedestrian facilities & 4 & 14.3 \\
No need to change & 3 & 10.7 \\
Walkways & 2 & 7.1 \\
Security & 2 & 7.1 \\
Sales and promotions & 1 & 3.6 \\
Halal food & 1 & 3.6 \\
Tourist attraction spots & 1 & 3.6 \\
Too many buildings & 1 & 3.6 \\
Total & 28 & 100 \\
\hline \multicolumn{2}{c}{ (Source: the Author, 2018) }
\end{tabular}

Figure 4 presents the existing views of several tourists' attractions in the city of Kuala Lumpur. The places have gone through upgrading and improvements in the past years. The efforts to remaking these places continue in line with the aim to attract more tourists to the areas.

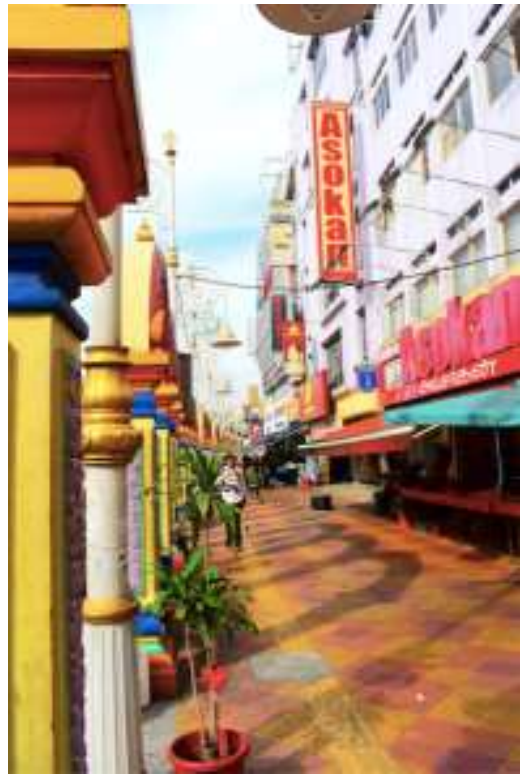

(a)

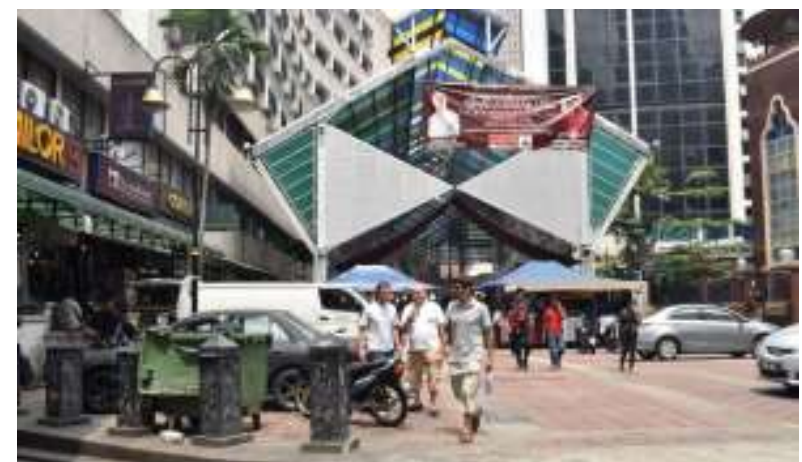

(c)

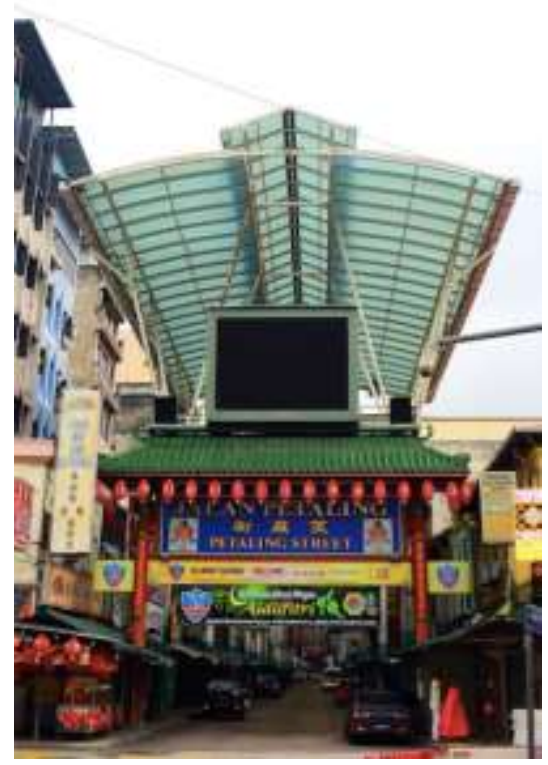

(b)

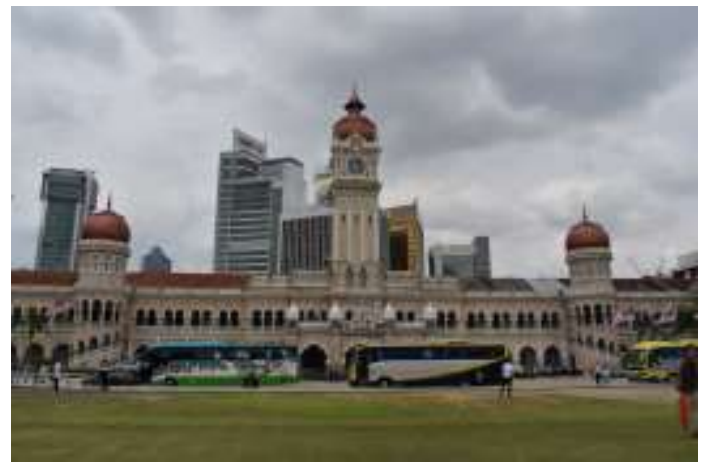

(d)

Fig. 4. The attractions in (a) Brickfields (b) Jalan Petaling (c) Jalan Masjid India and (d) Dataran Merdeka (Source: the Author, 2018)

\subsection{Discussion}

Visitors are one of the main stakeholders in a city. Their perspectives on places they visited matter in making the city meaningful to their experience. The attachment could be sensed through their intention of revisiting the places and their positive feeling that make them wanted to recommend the places to other people. This reaction, however, has not strongly linked to their satisfaction with the places as tourist attractions. A lot of changes needed to improve the place were mentioned covering the physical qualities, the image and the facilities provided. The strong image of Kampong Bharu and Chinatown and Brickfield captured the 
visitors' perception of the distinctiveness of the places. This response concurs with the findings by Smaldone (2005) that place dependence is influenced by the qualities associated with the current place. However, in the context of tourism experience, the outcome could be linked to the comparison made to similar historic sites in other parts of Malaysia or worldwide that the tourists had visited or had known previously. Dependence here can be linked to the need to be in place to fulfil visual and psychological needs and fulfilment rather than for life sustenance.

Despite having the unique traditional image and culture of multi-ethnicity (Malay, Chinese and Indian), there were concerns about the lack of greenery in the city, lack of parking and tourist facilities. The plan to regenerate the places for tourism purpose has not been regarded as adequate since the places are mostly tourist-unfriendly places in its present condition. Safety and security, as well as walkability, has been an ongoing issue for Kuala Lumpur city centre. A stronger attachment to attractive tourism places encourages frequent visits and longer time spending. It will help to attract more visitors to experience places, encouraging the urban economy and forming a positive image of the city. It is evident that the traditional image and identity were identified as the strength of the places and they should be preserved and sustained. The mixed cultural expressions correlate with the melting pot of the population which continues to define the uniqueness of tourism places in the city alongside the modern and global image of new commercial centres that is attractive to foreign countries.

The tourists were coming mainly for short trips, and transit thus could influence the way the places were perceived and experienced and their fair level of attachment. However, repeated mentioned regarding the need to have more greenery and parks or open spaces for relaxation and leisure indicate the concern over the comfort and image of the places in supporting tourists' activities. People's movement in the city should be balanced by having spaces to sit and relax. The car-oriented [less pedestrian-oriented] places contribute to the feeling of discomfort and insecurity among the visitors.

The idea of the future regeneration of tourism places was linked to the need to shape the places based on the existing nature of the places (historical and cultural attractions), eg traditional market, street vendors, food junction, traditional cultural centers, museum and art galleries, and historic attraction to support cultural and artistic events. Regardless of the inclination of Kuala Lumpur as business tourism, e.g. shopping, trading and health (medical), the choices of having these cultural related urban tourism is highlighted more strongly. The effort to regenerate the Kuala Lumpur riverfront at present should support these functions considering the vital role of culture in shaping the identity of Kuala Lumpur from the beginning of its development. Therefore the concept of regeneration should be addressed in the context of sustainability and continuity of place image and identity together with comfortability and accessibility of the places to the users.

\subsection{Conclusion and Recommendations}

Place regeneration is a vital process in making places and to stay relevant in the midst of urban transformation. Attachment to places functions as a supporting element to sustain place attraction. The feedback from visitors' who have a certain level of attachment with the places could be referred to as relevant points in regenerating places. Any physical intervention should consider the characteristics that are unique to the place [that the visitors' attached to and identified with] to be preserved and protected. The comfort of experiencing the place either by vehicles or on foot need to be ensured by providing complete and up to date tourist facilities; integrating more softscape, trees and greenery along the visitor's movement and destinations. The accessibility along the pedestrian network will support more tourist-friendly environment that connects the visitors with other attractions in the city centre. The framework for the final phase of this study should be framed based on the findings discussed in this paper.

\section{Acknowledgement}

The authors acknowledge Universiti Putra Malaysia for funding and facilitating the research under the Putra Grant Scheme (UPM/ 7002/1/GP- IP/2016/9483500)

\section{References}

Altman, I. \& Low, S. (1992). Place attachment. New York: Plenum Press

Awang, Khairil Wahidin and Abdul Aziz, Yuhanis (2010). Tourism policy development: a Malaysian experience. Journal of Tourism, Hospitality and Culinary Arts, 2 (2), 53-62

Cave, J \& Jolliffe, L. (2012) Urban Tourism. Tourism: The Key Concepts. Robinson, P. (Ed.) London: Routledge. pp 268-270

Craggs, R. \& Schofield, (2011).The quays in salford: an analysis of visitor perceptions, satisfaction and behavioural intention, International Journal of Tourism Research, 13 (6), 583-599

De Vaus, D. (2001). Research design in social research: Sage Publications Limited

Economic Planning Unit (EPU). Eleventh Malaysia Plan 2016-2020, [Online available at : http://www.epu.gov.my/en/eleventh-malaysia-plan-2016-2020 [accessed Aug 26 2018] 
Gross, M.J. Brien, C. \& Brown, G. (2008). Examining the dimensions of a lifestyle tourism destination, International Journal of Culture, Tourism and Hospitality Research 2(1), 44-66

Hidalgo M. C., and Hernandez, B. (2001). 'Place Attachment: Conceptual and Empirical Questions.' Journal of Environmental Psychology, 21, 273-281.

Hwang, S. N., Lee, C., \& Chen, H. J. (2005). 'The Relationship among Tourists' Involvement, Place attachment and Interpretation Satisfaction in Taiwan's National Parks.' Tourism Management, 26: 143-156

Kuala Lumpur City Hall (2015). Kuala Lumpur Tourism Master Plan 2015-2025. Available from: http://www.kltourismmasterplan.com/the-masterplan/ accessed Aug 262018

Moore, R. L., \& Graefe, A. R. (1994). Attachment to recreation settings: The case of rail-trail users. Leisure Sciences, 16, 17-31

Morgan, N., A. Pritchard, R. Pride, (2004). Destination branding - Creating the unique destination proposition, 2nd Edition, Butterworth-Heinemann, Oxford

Pallant, J. (2013). SPSS survival manual. McGraw-Hill Education (UK).

Ramlee, M., Omar, D., Mohd Yunus, R., Samadi, Z. (2018). Attributes of Successful Public Spaces through Users Perception. Asian Journal of Quality of Life (AjQoL), 3(11), 21-28

Said, S.Y. (2018). Urban Regeneration and Conservation of Historic Areas in Malaysia, Asian Journal of Behavioural Studies (AjBeS), 3(11), 201-210

Samadi, Z. \& Mohd Yunus, R. (2018). Urban Heritage Streets' Revitalising Attributes, Asian journal of Environment-Behaviour Studies (ajE-Bs), 3(6), 191 - 119

Smaldone, D. , Harris, C. , and Sanyal, N. (2005). An exploration of place as a process : The case of Jackson Hole, WY. Journal Of Environmental Psychology, $25,397-414$.

Stokols, D. and Shumaker, S. A. (1981). People in places : A transactional view of settings.. In Harvey, J. H. (Ed.). Cognition social behaviour and the environment. (pp.441-488) Hillsdale, NJ. Lawrence Erlbaum Assoc.

Ujang, N., \& Zakariya, K. (2015). Place attachment and the value of place in the life of the users. Procedia - Social and Behavioral Sciences, 168, 373-380

Ujang, N. \& Shuhana, S. (2008). Place Attachment In Relation to Users' Roles In The Main Shopping Streets Of Kuala Lumpur. Urban Design Issues in Developing World, Edited by Ahmad Bashri Sulaiman and Moukhtar.M.Mai. 22-41, UTM Press (Limited Edition) 